\title{
Ethiopian summer temperature from the global circulation model output data and its outlooks
}

Solomon Addisu Legesse

\begin{abstract}
Background: Agriculture is the most susceptible sector to climate change related hazards in Ethiopia. Any minor change in temperature from the normal conditions imposes a severe challenge on the agricultural dependent people of Ethiopia. This research work, entitled 'Ethiopian Summer Temperature from the Global Circulation Model Output Data and its Outlooks' has been conducted to fill such knowledge gaps of the target population. The objective of the research was to analyze summer temperature from the global circulation model output data and its outlooks with the change of global climate. To attain this specific objective, global circulation model output data were used. These data were analyzed by using Xcon, Matlab and Grid Analysis and Display System computer software programs.

Results: The results revealed that the mean temperature has shown a general increasing trend $\left(0.548^{\circ} \mathrm{C}\right)$ since 1971-2010. The best performed models having similar trends to the historical observed temperature data analysis predicted that the future summer mean temperature has been predicted to increase by $0.59^{\circ} \mathrm{C}$ (model bccr) and $0.743^{\circ} \mathrm{C}$ (model cccma) from 2015 to 2054.

Conclusion: It is therefore recommended that the legislative bodies and development planners should design strategies and plans by taking into account impacts of increasing temperature on rural livelihoods. Moreover, adverse impacts of climate change and adaptation strategies should be a crosscutting issue.
\end{abstract}

Keywords: Global circulation model, Climate change, Temperature, Ethiopian summer

\section{Background}

Model simulations show wide disagreements in projected changes in the amplitude of future climate conditions (Temesgen et al. 2014). Ethiopian highlands seasonal rainfall in particular and East Africa's seasonal rainfall can be strongly influenced by the surface temperature and pressure variations across the tropical eastern pacific ocean warming and cooling (El Nino and La Ninas) respectively. And this attribute to ambiguity in climate forecasts, predominantly in the future inter-annual variability (McSweeney et al. 2008).

According to IPCC (2001a) report, Africa had already warmed by $0.7{ }^{\circ} \mathrm{C}$ over the twentieth century. Many researches based on the outputs of general circulation

*Correspondence: soladd2000@yahoo.com

Department of Natural Resources Management, College of Agriculture and Environmental Sciences, Bahir Dar University, Bahir Dar, Ethiopia models (GCMs) showed that the continent could be warming by temperature ranging from $0.2{ }^{\circ} \mathrm{C}$ per decade (low scenario) to more than $0.5^{\circ} \mathrm{C}$ per decade (high scenario) (McSweeney et al. 2008).

Simulation of future climate for 2030 and 2050 Canadian Climate Center Model, CCCM; Geophysical Fluid Dynamics Laboratory Model (GFDL), the United Kingdom Meteorological Office-1989 model, (UKMO-89); and GFDL-Transient Models indicated an increase in temperature and a decrease in rainfall over Ethiopia (NMSA 2001). According to this simulation study, there will be an increase in temperature and a decrease of rainfall by about 1 and $2 \%$ by 2030 and 2050, respectively. These changes in rainfall and temperature are expected to decrease revenue per hectare. Although the exact nature of the changes in weather conditions, and extreme events are not known and still controversial, there is general 
consensus that extreme events will increase and may get worse (UNFCCC 2006). According to IPCC (2001a, b), changes will be manifested in some extreme climate phenomena indicating that extreme events, including flood and drought, will be increasingly frequent and severe in Africa, particularly in the Horn of Africa where Ethiopia is the core. According to Elasha et al. (2006), frequently occurring types of disasters in Ethiopia is drought, flood, landslide, thunderstorms accompanied by lightning and hail, frost, forest fire, and earthquake. The first two are the most common. Associated with adverse weather conditions, outbreaks of locusts (on crops), tsetse fly (a vector for trypanosomiasis), human disease outbreak like yellow fever, malaria and meningitis were also observed. Flooding and drought are now common across Ethiopia. It is probable that the increased frequency of recorded disasters results from a combination of climatic change and socioeconomic and demographic changes (UNFCCC 2006).

GCMs have been employed to study the impacts of increased greenhouse gas concentrations on future climate conditions. The model data estimates changes for dozens of meteorological variables for grid boxes that are typically $250 \mathrm{~km}$ in width and $600 \mathrm{~km}$ in length or (2.5 latitude and $3.75^{\circ}$ longitudes). Their resolution is therefore quite coarse. The most advanced GCMs couple atmosphere and ocean models and are mentioned to as coupled ocean-atmosphere GCMs (Schindelegger and Ray 2014). Two types of GCM runs can be useful for impact assessments.

Almost all GCMs have been practiced to simulate both current $\left(1 \mathrm{CO}_{2}\right)$ and future $\left(2 \mathrm{CO}_{2}\right.$ or occasionally $4 \mathrm{CO}_{2}$ ) climate conditions. The difference between these simulated climates is a scenario of how climate may change with an effective doubling (or quadrupling) of atmospheric $\mathrm{CO}_{2}$. Hence, it is referred to as equilibrium experiments since both the current and future climates are assumed by modelers to be in equilibrium i.e., stationary. GCMs used for equilibrium experiments generally have just a very simple representation of the oceans. To be sure, the climate is never in equilibrium (Schindelegger and Ray 2014). Greenhouse gas concentrations are not kept constant, because of human activities or other causes. The assumption of a stable climate makes it milder; however, climate modelers applied to calculate the effect of increased greenhouse gases on climate and for impact assessors to examine potential influences.

Hence, the specific objectives of this research was to examine the global circulation model output temperature data over Ethiopian summer for the past 40 years (1971-2010) and its 40 years future predictions (2015-2054).

\section{Materials and methods}

\section{Description of the study area}

Ethiopia is located in Northeastern or East Central Horn of Africa lying between 3 and $15^{\circ}$ north latitude, 33 to $48^{\circ}$ east longitude. Ethiopia is bordered in the east Somalia and Djibouti, in the south by Kenya, in the northeast by Eritrea and in the west by the North and South Sudan. The country has a total area of about 1.1 million $\mathrm{km}^{2}$ and comprises of 12 river basins with varying size and water resource potential (CSA 2007). Diverse rainfall and temperature patterns are largely the results of Ethiopia's location in Africa's tropical zone and the country's varied landscape. Elevation induced climatic conditions form the basis for three environmental zones as cool, temperate, and hot, which have been known locally as dega, weinadega, and kolla, respectively. The central parts of the western and eastern sections of the northwestern plateau and a small area around Harer are covered the cool zone. The topography in these areas is generally above 2400 m.a.s.l. in altitude; average daily highs ranges from near freezing to $16{ }^{\circ} \mathrm{C}$. Areas between 1500 and 2400 m.a.s.l. in elevation constitute the temperate zone. Daily highs range from 16 to $30{ }^{\circ} \mathrm{C}$. The hot zone consists of areas where the altitude is lower than 1, 500 m.a.s.l. This part of the region encompasses the eastern Ogaden, Denakil depression, the deep tropical valleys of the Blue Nile River and the peripheral areas along the South Sudanese and the Kenyan borders (UNEP 2007).

The computer software programs which were used for this study are Matlab (Mathematical modeling), Grid Analysis and Display System and Xcon (X converter).

\section{Methods}

For the accuracy and reliability of the real climate situation of the study area, observed climate station data from different sites and more sophisticated and recent models' output data were used. GCMs output data were used to simulate the climatic effect of increased atmospheric concentration of greenhouse gases (GHGs) and the climate model output was interpolated to the scale of Ethiopia using a regular grid bilinear interpolation method. The interpolated climate data were consisting of IPCC core variable such as temperature in the study area. This was determined by the local knowledge and experts' opinion of the study area. The performance of GCM was evaluated and the best model, which has a high hit rate for the observed data was used to predict the future temperature.

\section{GCM output data acquisition}

For the period from 1971 to 2010 and from 2015 to 2054, appropriate scenarios were selected based on the data availability. These data represent a subset of the 
IPCC model output archive run by Program for Climate Model Diagnosis and Inter-comparison (PCMDI). The complete set of core data variables in monthly temporal resolution was obtained from the IPCC-data distribution center (IPCC-DDC), at the website http://www.ipccdata. $\mathrm{org} / \mathrm{gcm} / \mathrm{monthly} /$ SRES_AR4/index.html. Since the data were developed for global scale and is at a suitable spatial resolution, the extent of Ethiopia was considered for selected high performance model data output. This was done by bilinear interpolation Xcon computer program (Yatagai et al. 2009).

The future climate predictions provide information on the actual values of climatic variables (e.g. temperature, which are common in the study area). On their own, they don't give any indication about the magnitude of change from the present day. That is the reason that the low resolution present day datasets for each corresponding model are required to provide baseline information which allows estimation of the magnitude of climate change.

\section{NCEP data}

Observations are from many different sources, including satellites, ship, ground stations, and radar. Currently, earth system research laboratory, physical sciences division (PSD) makes available these reanalysis datasets to the public in standard netCDF file format at the website '10.1175/15200477(1996)077\%3C0437\%3ATNYRP\%3 E2.0.CO\%3B2'. It is possible to extract useful information about rainfall, temperature and humidity observation from satellites, or to infer large-scale features of the global circulation in the early twentieth century using only surface pressure observations available at that time (Compo et al. 2011). Reanalysis is a rapidly evolving field and new reanalysis products benefit from recent modeling capabilities, improved techniques in data assimilation, in the latest observation techniques (i.e. from satellite measurements), and newly digitalized historical datasets (Compo et al. 2011). Reanalysis also allows the user to estimate temperature over regions where in situ observations are not available (e.g. Polar Regions, or large areas of Africa). In recent years, datasets from reanalysis have been widely used for research in the atmospheric and ocean sciences and in climate services. Reanalysis data were downloaded from the website of Earth System Laboratory Physical Science Division (ESL-PSD). This dataset for Ethiopian summer comprises monthly temperature of each year from 1971 to 2010 at a resolution of $0.5^{\circ}$ (approximately $55 \mathrm{~km}$ at the equator) were downloaded and crucially contains the climate variables which are common parameters to Ethiopia. This period was selected since the observation data before 1971 was not reliable and digital in the case of Ethiopia. It has been since 1971 that modern and standardized meteorological weather instruments were installed by (World Meteorological Organization) WMO standards (NMSA 2007).

\section{Data analysis}

In accordance with current best practice for analyzing the outputs of climate modeling exercises, the data from six runs of six different climate models were used. The model name and its origin are stated in Table 1.

A total of 23.6 GB data were downloaded and stored. The data were available in netCDF file format which is not a flat file construction, relatively a self-describing multi-layered structure for storing and documenting large amounts of numerical temperature data files. Each file downloaded contains monthly data for all years for the entire earth. In order to extract 'slices' of the multilayered NetCDF datasets, it was necessary to use certain tools which were designed specifically for the NetCDF file format. The climate data analysis tool was (Xcon) was downloaded. Using this software, both temporal (1971-2054) and spatial (from the global scale to Ethiopian latitudinal and longitudinal extent) slices of a NetCDF file were extracted. It was important to recognize that from a temporal perspective, what was actually extracted were the monthly normal calculated from the data for 40 years either side of the year of interest. The reason for calculating monthly normal was to eliminate single year anomalies that may show up in the temperature data from a single year only. Due to the spatial sub-setting routine to remove data outside of Ethiopia, in addition to the calculation of monthly normal, the size of this entire data set was reduced from 23.6 GB to $210 \mathrm{MB}$. Further compression has reduced the total size of the dataset.

The mask file was prepared using excel sheet by putting a zero value for areas not touched and one value for areas covered by the latitudinal and longitudinal extent of Ethiopia. This value was used to limit the study only for the area covered by map of Ethiopia. The mathematical modeling (Matlab) cod (program was developed to calculate the different statistical analysis, such as climatology (clim), standard deviation (sd), root mean square errors (rmse), Coefficient of variations (cv) and correlations (corr) (Fig. 1).

\section{Results and discussions}

\section{Summer temperature and GCM output data}

The historical temperature record was analyzed by dividing into two periods (1971 to 1990 and from 1991 to 2010 (Legesse 2016). Likewise, the future summer temperature predictions were made based on the period category of 2015-2034 and 2035-2054. Accordingly, each of the subperiod analysis is stated in the following sections. 
Table 1 Summary of the models used for temperature variable

\begin{tabular}{llllll}
\hline Country of run & Model name & Run & $\begin{array}{l}\text { Surface air } \\
\text { temp. m(tas.) }\end{array}$ & $\begin{array}{l}\text { Max. monthly air surface } \\
\text { temp. at 2 m (tasmax.) }\end{array}$ & $\begin{array}{l}\text { Min. monthly surface } \\
\text { temp. at 2 m (tasmin.) }\end{array}$ \\
\hline Norway & bccr-bcm2.0 & 1 & $\sqrt{ }$ & $\sqrt{ }$ & $\sqrt{ }$ \\
Canada & cccma_cgcm3_1 & 1 & $\sqrt{ }$ & & $\sqrt{ }$ \\
USA & giss_model_e_r & 1 & $\sqrt{ }$ & & \\
Russia & inmcm3_0 & 1 & $\sqrt{ }$ & \\
France & ipsl_cm4 & 3 & $\sqrt{ }$ & \\
Germany & echam-5 & 3 & $\sqrt{ }$ & \\
\hline
\end{tabular}

\begin{tabular}{|c|c|c|c|c|c|c|c|c|c|c|c|c|c|c|c|c|c|c|c|c|c|c|c|c|c|c|c|c|c|c|c|}
\hline & 33 & 33.5 & & 34.5 & 35 & 35.5 & & 36.5 & & 37.5 & 38 & 38.5 & 39 & 39.5 & & 40.5 & & 41.5 & & 42.5 & 43 & 43.5 & 44 & 44.5 & 45 & 45.5 & 46 & 46.5 & 47 & 47.54 & \\
\hline 15 & 0 & 0 & 0 & 0 & 0 & 0 & 0 & 0 & 0 & 0 & 0 & 0 & 0 & 0 & 0 & 0 & 0 & 0 & 0 & 0 & 0 & 0 & 0 & 0 & 0 & 0 & 0 & 0 & 0 & 0 & \\
\hline 14.5 & 0 & 0 & 0 & 0 & 0 & 0 & 0 & 0 & 0 & 0 & 0 & 0 & 0 & 0 & 0 & 0 & 0 & 0 & 0 & 0 & 0 & 0 & 0 & 0 & 0 & 0 & 0 & 0 & 0 & 0 & \\
\hline 14 & 0 & 0 & 0 & 0 & 0 & 0 & 0 & 1 & 1 & 1 & 1 & 1 & 1 & 1 & 1 & 1 & 0 & 0 & 0 & 0 & 0 & 0 & 0 & 0 & 0 & 0 & 0 & 0 & 0 & 0 & 0 \\
\hline 13.5 & 0 & 0 & 0 & 0 & 0 & 0 & 0 & 1 & 1 & 1 & 1 & 1 & 1 & 1 & 1 & 1 & 1 & 1 & 0 & 0 & 0 & 0 & 0 & 0 & 0 & 0 & 0 & 0 & 0 & 0 & 0 \\
\hline 13 & 0 & 0 & 0 & 0 & 0 & 0 & 1 & 1 & 1 & 1 & 1 & 1 & 1 & 1 & 1 & 1 & 1 & 1 & 1 & 0 & 0 & 0 & 0 & 0 & 0 & 0 & 0 & 0 & 0 & 0 & \\
\hline 12.5 & 0 & 0 & 0 & 0 & 0 & 1 & 1 & 1 & 1 & 1 & 1 & 1 & 1 & 1 & 1 & 1 & 1 & 1 & 1 & 1 & 0 & 0 & 0 & 0 & 0 & 0 & 0 & 0 & 0 & & \\
\hline 12 & 0 & 0 & 0 & 0 & 0 & 1 & 1 & 1 & 1 & 1 & 1 & 1 & 1 & 1 & 1 & 1 & 1 & 1 & 1 & 0 & 0 & 0 & 0 & 0 & 0 & 0 & 0 & 0 & 0 & 0 & 0 \\
\hline 11.5 & 0 & 0 & 0 & 0 & 1 & 1 & 1 & 1 & 1 & 1 & 1 & 1 & 1 & 1 & 1 & 1 & 1 & 1 & 0 & 0 & 0 & 0 & 0 & 0 & 0 & 0 & 0 & 0 & 0 & & 0 \\
\hline 11 & 0 & 0 & 0 & 0 & 1 & 1 & 1 & 1 & 1 & 1 & 1 & 1 & 1 & 1 & 1 & 1 & 1 & 1 & 0 & 0 & 0 & 0 & 0 & 0 & 0 & 0 & 0 & 0 & 0 & 0 & 0 \\
\hline 10.5 & 0 & 0 & 1 & 1 & 1 & 1 & 1 & 1 & 1 & 1 & 1 & 1 & 1 & 1 & 1 & 1 & 1 & 1 & 1 & 1 & 0 & 0 & 0 & 0 & 0 & 0 & 0 & 0 & 0 & 0 & 0 \\
\hline 10 & 0 & 0 & 1 & 1 & 1 & 1 & 1 & 1 & 1 & 1 & 1 & 1 & 1 & 1 & 1 & 1 & 1 & 1 & 1 & 1 & 0 & 0 & 0 & 0 & 0 & 0 & 0 & 0 & 0 & 0 & 0 \\
\hline 9.5 & 0 & 0 & 1 & 1 & 1 & 1 & 1 & 1 & 1 & 1 & 1 & 1 & 1 & 1 & 1 & 1 & 1 & 1 & 1 & 1 & 1 & 0 & 0 & 0 & 0 & 0 & 0 & 0 & 0 & 0 & 0 \\
\hline 9 & 0 & 0 & 1 & 1 & 1 & 1 & 1 & 1 & 1 & 1 & 1 & 1 & 1 & 1 & 1 & 1 & 1 & 1 & 1 & 1 & 1 & 1 & 0 & 0 & 0 & 0 & 0 & 0 & 0 & 0 & 0 \\
\hline 8.5 & 0 & 0 & 1 & 1 & 1 & 1 & 1 & 1 & 1 & 1 & 1 & 1 & 1 & 1 & 1 & 1 & 1 & 1 & 1 & 1 & 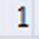 & 1 & 1 & 1 & 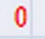 & 0 & 0 & 0 & 0 & 0 & 0 \\
\hline 8 & 1 & 1 & 1 & 1 & 1 & 1 & 1 & 1 & 1 & 1 & 1 & 1 & 1 & 1 & 1 & 1 & 1 & 1 & 1 & 1 & 1 & 1 & 1 & 1 & 1 & 1 & 1 & 1 & 0 & 0 & 0 \\
\hline 7.5 & 1 & 1 & 1 & 1 & 1 & 1 & 1 & 1 & 1 & 1 & 1 & 1 & 1 & 1 & 1 & 1 & 1 & 1 & 1 & 1 & 1 & 1 & 1 & 1 & 1 & 1 & 1 & 1 & 1 & 1 & 0 \\
\hline 7 & 0 & 1 & 1 & 1 & 1 & 1 & 1 & 1 & 1 & 1 & 1 & 1 & 1 & 1 & 1 & 1 & 1 & 1 & 1 & 1 & 1 & 1 & 1 & 1 & 1 & 1 & 1 & 1 & 1 & 0 & 이 \\
\hline 6.5 & 0 & 0 & 1 & 1 & 1 & 1 & 1 & 1 & 1 & 1 & 1 & 1 & 1 & 1 & 1 & 1 & 1 & 1 & 1 & 1 & 1 & 1 & 1 & 1 & 1 & 1 & 1 & 1 & 0 & 0 & 0 \\
\hline 6 & 0 & 0 & 0 & 1 & 1 & 1 & 1 & 1 & 1 & 1 & 1 & 1 & 1 & 1 & 1 & 1 & 1 & 1 & 1 & 1 & 1 & 1 & 1 & 1 & 1 & 1 & 1 & 0 & 0 & 0 & 0 \\
\hline 5.5 & 0 & 0 & 0 & 1 & 1 & 1 & 1 & 1 & 1 & 1 & 1 & 1 & 1 & 1 & 1 & 1 & 1 & 1 & 1 & 1 & 1 & 1 & 1 & 1 & 1 & 1 & 0 & 0 & 0 & 0 & 0 \\
\hline 5 & 0 & 0 & 0 & 0 & 0 & 1 & 1 & 1 & 1 & 1 & 1 & 1 & 1 & 1 & 1 & 1 & 1 & 1 & 1 & 1 & 1 & 1 & 1 & 1 & 1 & 1 & 0 & 0 & 0 & 0 & 0 \\
\hline 4.5 & 0 & 0 & 0 & 0 & 0 & 1 & 1 & 1 & 1 & 1 & 1 & 1 & 1 & 1 & 1 & 1 & 1 & 1 & 1 & 1 & 1 & 0 & 0 & 0 & 0 & 0 & 0 & 0 & 0 & 0 & 0 \\
\hline 4 & 0 & 0 & 0 & 0 & 0 & 0 & 0 & 0 & 1 & 1 & 1 & 1 & 1 & 1 & 1 & 1 & 1 & 1 & 1 & 1 & 0 & 0 & 0 & 0 & 0 & 0 & 0 & 0 & 0 & 0 & 0 \\
\hline 3.5 & 0 & 0 & 0 & 0 & 0 & 0 & 0 & 0 & 0 & 1 & 1 & 1 & 1 & 0 & 0 & 0 & 0 & 0 & 0 & 0 & 0 & 0 & 0 & 0 & 0 & 0 & 0 & 0 & 0 & 0 & 0 \\
\hline 3 & 0 & 0 & 0 & 0 & 0 & 0 & 0 & 0 & 0 & 0 & 1 & 1 & 0 & 0 & 0 & 0 & 0 & 0 & 0 & 0 & 0 & 0 & 0 & 0 & 0 & 0 & 0 & 0 & 0 & 0 & 0 \\
\hline
\end{tabular}

Fig. 1 Mask file of Ethiopia

\section{Summer temperature trends (1971-1990)}

Even though the standard deviation and coefficient of variation did not Mach, the modal value which has a similar record to the observation $\left(20.58^{\circ} \mathrm{C}\right)$ is $\operatorname{bccr}\left(20.62{ }^{\circ} \mathrm{C}\right)$ by long year's average (clim.) statistics. Model inmcm also has a better record with a coefficient of variations.
The smaller magnitude of rmse and bias values by model inmcm is found to be (5.201 and 5.132), respectively. Therefore, this model performed well as compared to the rest of the modules (Table 2). Hence, it has been clear that model $b c c r$ recorded the closet value to an observed temperature record. 
Table 2 Statistical analysis of summer temperature (1971-1990)

\begin{tabular}{|c|c|c|c|c|c|c|}
\hline Model & $\mathrm{Clim}\left({ }^{\circ} \mathrm{C}\right)$ & sd & $\mathrm{cv}$ & corr & rmse & bais \\
\hline NNRP & 20.575 & 0.714 & 3.472 & & & \\
\hline$b c c r$ & 20.617 & 0.335 & 1.625 & 0.301 & 0.693 & 0.042 \\
\hline cccma & 30.583 & 0.442 & 1.445 & -0.427 & 12.049 & 10.008 \\
\hline echam & 28.443 & 1.115 & 3.920 & -0.187 & 7.998 & 7.868 \\
\hline giss & 26.843 & 0.273 & 1.017 & 0.061 & 6.313 & 6.268 \\
\hline inmem & 25.707 & 0.482 & 1.876 & 0.049 & 5.201 & 5.132 \\
\hline ipsl & 28.446 & 0.284 & 0.998 & 0.142 & 7.905 & 7.871 \\
\hline
\end{tabular}

Table 3 POD of models for summer temperature

\begin{tabular}{lllll}
\hline Model & Worm & Cold & Normal & Combined \\
\hline bccr & 0.5 & 0.33 & 0.77 & 0.65 \\
cccma & 0 & 0 & 0.7 & 0.45 \\
echam & 0.25 & 0 & 0.77 & 0.55 \\
giss & 0.25 & 0.33 & 0.54 & 0.45 \\
inmcm & 0.25 & 0 & 0.7 & 0.5 \\
ipsl & 0 & 0 & 0.46 & 0.3 \\
\hline
\end{tabular}

\section{Probability of detection (POD)}

From the normalized anomaly calculations, the POD value of models has been computed. Accordingly, the warm, cold and normal temperature detection has been captured by model bccr (50, 33 and 77\%), respectively. The combined detection power of models has also shown that model $b c c r$ (65\%) performed best as compared to others (Table 3).

Based on the observation of the temperature record, most of the years were normal. However, the years 1973, 1978, 1985 and 1988 have been found to be warm; whereas the years 1975, 1983 and 1984 were relatively colder. The model which recorded a similar value was bccr as compared to other models (Table 4).

The GrADS generation of the summer temperature has depicted that higher temperature was recorded in the eastern, western and southeastern lowlands of the country by the observation record; whereas, the lower

Table 4 Normalized anomaly of summer temperature

\begin{tabular}{|c|c|c|c|c|c|c|c|}
\hline \multirow[t]{2}{*}{ Year } & \multicolumn{7}{|l|}{ Model } \\
\hline & $N N R P$ & $b c c r$ & cccma & echam & giss & inmcm & ipsl \\
\hline 1971 & -0.253 & -0.171 & -0.240 & 1.052 & -0.940 & 0.938 & -1.356 \\
\hline 1972 & -0.418 & -0.968 & 0.669 & 0.222 & 1.109 & 1.027 & 1.206 \\
\hline 1973 & $1.198^{b}$ & 1.213 & 0.589 & -0.870 & -0.442 & 0.830 & -1.118 \\
\hline 1974 & 0.178 & -0.090 & 0.185 & 0.238 & -0.805 & -0.783 & 2.244 \\
\hline 1975 & $-1.264^{\mathrm{a}}$ & 0.543 & -0.279 & 0.791 & -1.431 & 0.258 & -0.641 \\
\hline 1976 & -0.874 & -2.295 & -0.142 & -1.060 & 1.879 & -0.643 & -0.232 \\
\hline 1977 & 0.596 & -0.349 & -2.499 & -0.590 & 0.275 & -2.158 & -0.027 \\
\hline 1978 & $1.532^{b}$ & -0.970 & 0.128 & 1.287 & 1.492 & 1.212 & 0.313 \\
\hline 1979 & -0.077 & -1.034 & -1.349 & -0.313 & 0.278 & 0.713 & 1.155 \\
\hline 1980 & 0.581 & -0.079 & 0.874 & -2.735 & -0.021 & 0.976 & 0.411 \\
\hline 1981 & -0.079 & 0.184 & 0.152 & -0.954 & -1.711 & 0.735 & 0.510 \\
\hline 1982 & 0.462 & -0.416 & 1.373 & 0.594 & 1.040 & 0.392 & 0.383 \\
\hline 1983 & $-2.329^{\mathrm{a}}$ & -1.377 & 1.781 & 1.641 & 0.157 & 0.707 & 0.167 \\
\hline 1984 & $-1.557^{a}$ & 0.742 & 0.428 & -0.785 & 0.745 & 0.245 & -0.768 \\
\hline 1985 & $1.357^{b}$ & -0.127 & -1.069 & -0.861 & -1.077 & 0.252 & 0.535 \\
\hline 1986 & 0.427 & 0.816 & -0.814 & 0.584 & 0.275 & -0.050 & 1.509 \\
\hline 1987 & 0.096 & 0.502 & -0.021 & 0.720 & -1.013 & -1.784 & -1.195 \\
\hline 1988 & $1.426^{b}$ & 2.184 & -1.248 & 0.574 & 0.699 & -0.351 & -0.819 \\
\hline 1989 & -0.855 & 0.665 & 1.212 & 0.018 & -1.153 & -1.928 & -1.341 \\
\hline 1990 & -0.145 & 1.028 & 0.270 & 0.445 & 0.645 & -0.590 & -0.935 \\
\hline
\end{tabular}

a Cold years

${ }^{\mathrm{b}}$ Warm years 
temperature has been recorded in the central highlands. Therefore, in this analysis model bccr and echam have a similar summer temperature pattern. The rest of the models failed to record Ethiopian summer temperature. Model cccma failed to record low temperature, whereas inmcm totally failed to capture the high temperature of Ethiopian summer (Fig. 2). Taking this value as a base, we can indicate the future temperature of Ethiopian summer using model $b c c r$. In fact the overall value should be used to decide the best performed model for prediction.

\section{Summer temperature trends (1991-2010)}

The summer mean temperature record to the observation for the period $1991-2010$ was found to be $21.12{ }^{\circ} \mathrm{C}$. The mean temperature has shown $0.55{ }^{\circ} \mathrm{C}$ increment from the period 1971-1990. Model value, which has a similar summer temperature record by clim, is model $b c c r$ $\left(21.283{ }^{\circ} \mathrm{C}\right)$; whereas, by the sd. value, model $c c c m a$ has similar record than $b c c r$ to the observed value. In addition, model echam has similar record by coefficient of variation than the rest of the models. Moreover, the smaller recorded magnitude value of the rmse and bias value were recorded by model $b c c r(0.862)$ and (0.160), respectively. Therefore, model $b c c r$ has a high probability to record summer mean temperature with a similar record to that of the observed (Table 5). This result is in line with the previous period (1971-1990). The overall performance of this model is good and enabled to predict the future summer temperature of Ethiopia. Models such as cccma, echam and ipsl have over recorded the summer temperature.

The model bccr, giss and and inmcm have been detected the warm, cold and normal summer temperature from

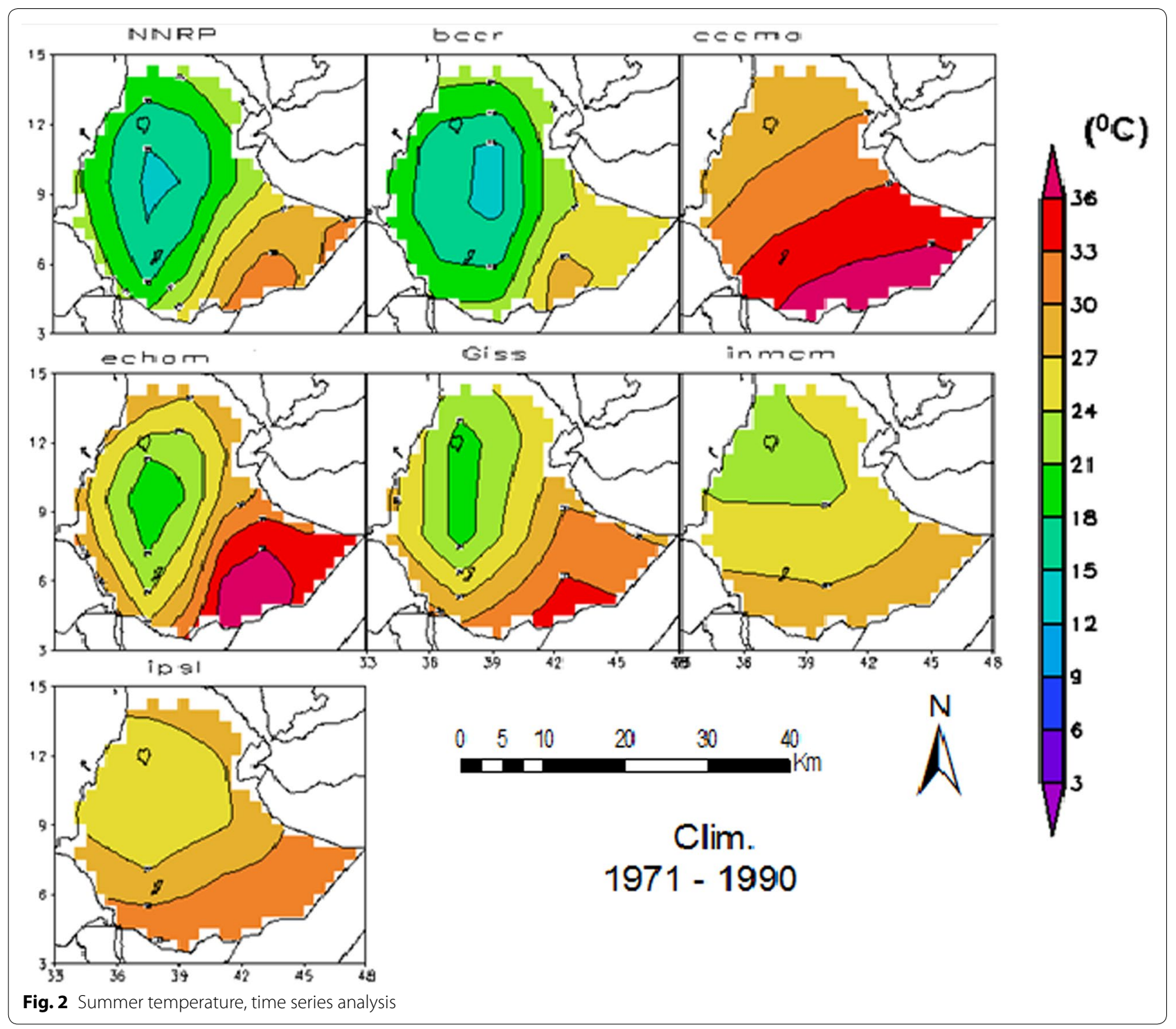


Table 5 Statistical analysis of summer temperature from 1991 to 2010

\begin{tabular}{|c|c|c|c|c|c|c|}
\hline Model name & $\mathrm{Clim}\left({ }^{\circ} \mathrm{C}\right)$ & sd & $\mathrm{cv}$ & corr & rmse & bias \\
\hline NNRP & 21.122 & 0.695 & 3.290 & & & \\
\hline$b c c r$ & 21.283 & 0.417 & 1.959 & 0.105 & 0.862 & 0.160 \\
\hline cccma & 31.510 & 0.574 & 1.822 & -0.320 & 11.435 & 10.388 \\
\hline echam & 28.491 & 0.945 & 3.318 & -0.013 & 7.463 & 7.369 \\
\hline giss & 27.003 & 0.346 & 1.280 & 0.022 & 5.931 & 5.881 \\
\hline inmem & 25.606 & 0.534 & 2.087 & -0.123 & 4.579 & 4.484 \\
\hline ipsl & 28.540 & 0.267 & 0.935 & 0.244 & 7.448 & 7.417 \\
\hline
\end{tabular}

Table 6 POD of models of summer temperature

\begin{tabular}{lllll}
\hline Model & Warm & Cold & Normal & Combined \\
\hline bccr & 0.33 & 0.5 & 0.82 & 0.60 \\
cccma & 0 & 0.25 & 0.73 & 0.45 \\
echam & 0.33 & 0 & 0.45 & 0.3 \\
giss & 0.33 & 0.25 & 0.45 & 0.35 \\
inmem & 0.33 & 0.25 & 0.64 & 0.45 \\
ipsl & 0 & 0.25 & 0.54 & 0.35 \\
\hline
\end{tabular}

the normalized anomaly calculations (Table 6). The probability of detection by the model bccr $(60 \%)$ is the highest and can be selected as the best performed model as compared to other models (Table 7). The probability of detecting warm temperature years have recorded better by most of the models than the probability of detecting the colder summer temperature. However, almost all of the models have shown that a normal summer temperature record and failed to record extreme temperature except $b c c r$ model.

Table 7 Normalized anomaly of summer temperature

\begin{tabular}{|c|c|c|c|c|c|c|c|}
\hline \multirow[t]{2}{*}{ Year } & \multicolumn{7}{|l|}{ Model } \\
\hline & $N N R P$ & $b c c r$ & cccma & echam & giss & inmcm & ipsl \\
\hline 1991 & $0.431^{* *}$ & -0.051 & -1.045 & 1.263 & -0.918 & -1.259 & -0.463 \\
\hline 1992 & $-1.478^{*}$ & -1.105 & 0.220 & -0.330 & 1.702 & 0.227 & -1.308 \\
\hline 1993 & $0.275^{* *}$ & -0.639 & -0.221 & -1.624 & 1.130 & 0.891 & 1.125 \\
\hline 1994 & $-0.77^{* *}$ & 0.045 & -1.451 & 0.732 & 1.074 & -0.763 & -0.817 \\
\hline 1995 & $-1.910^{*}$ & 1.772 & -0.507 & -0.465 & -1.517 & 0.884 & -0.479 \\
\hline 1996 & $0.88^{* *}$ & -0.562 & -0.928 & -1.654 & -0.998 & 1.103 & -1.816 \\
\hline 1997 & $-1.055^{*}$ & -1.152 & 0.474 & -0.365 & 0.476 & -1.178 & -0.505 \\
\hline 1998 & $1.310^{* * *}$ & 0.689 & -1.561 & 1.318 & 1.230 & -1.290 & 0.070 \\
\hline 1999 & $1.114^{* * *}$ & -0.435 & -0.530 & -1.600 & 0.190 & -0.656 & 0.895 \\
\hline 2000 & $-0.16^{* *}$ & -0.896 & 0.020 & -1.532 & -1.653 & -1.010 & 0.411 \\
\hline 2001 & $-0.34^{* *}$ & -0.316 & 1.833 & 0.797 & -0.386 & 1.006 & -1.158 \\
\hline 2002 & $0.91^{* *}$ & -0.478 & -0.108 & 0.592 & 1.292 & 0.844 & 1.447 \\
\hline 2003 & $-0.98^{* *}$ & -0.035 & -0.118 & 1.156 & 0.453 & 0.693 & 0.325 \\
\hline 2004 & $1.61^{* * *}$ & -1.578 & 0.390 & 0.533 & 0.561 & 2.027 & 0.307 \\
\hline 2005 & $-0.99 * *$ & -0.030 & 0.861 & 0.593 & -0.657 & 0.577 & 0.522 \\
\hline 2006 & $0.55^{* *}$ & -0.705 & 0.940 & -0.644 & -0.432 & -0.794 & -1.951 \\
\hline 2007 & $-1.167^{*}$ & 1.112 & 2.599 & -0.096 & 0.642 & 1.112 & 0.799 \\
\hline 2008 & $0.86^{* *}$ & 1.688 & -0.466 & -0.484 & -1.160 & -0.824 & 1.500 \\
\hline 2009 & $0.20^{* *}$ & 0.582 & -0.666 & 0.635 & -1.138 & -0.927 & 0.246 \\
\hline 2010 & $0.72^{* *}$ & 2.092 & 0.262 & 1.174 & 0.109 & -0.663 & 0.852 \\
\hline
\end{tabular}

${ }^{*}$ Cold years

${ }^{* *}$ Normal years

*** Warm years 
Based on the normalized anomaly table, the warm years by the observed temperature record were 1998, 1999 and 2004; whereas, the cold years were recorded in 1992, 1995, 1997 and 2007; and the remaining were normal temperature years. The model which has recorded closely related value to the observation is $b c c r$. It has a high hit rate as compared to others. This value again encourages the performance of the model better and it has the highest potential to use its future recorded value (Table 7).

The GrADS analysis of the summer temperature for the period 1991-2010 has recorded by the model bccr in a better performance than the rest of the models. Secondly, model echam and giss also have shown similar pattern though a little bit higher values of clim was recorded (Fig. 3). According to the summer temperature special and temporal patterns of the period 19912010, the model cccma, ipsl, inmcm, have been failed to capture similar temperature record to that of the observation. Model cccma failed to record the cold years and ipsl failed to record extreme summer temperature and it is hardly important to consider its value for the future. Model giss failed to record the colder years, however the pattern of summer temperature is not very far from the above models.

In general the past 40 year analysis of GCM output data has shown by the well performed model $b c c r$. Hence, it has indicated that a warming of summer temperature and a decreasing trend of summer monsoon rainfall over Ethiopia. These research findings are in line with other researchers. Gulilat et al. (2008) in their study indicated an investigation with three global climate models that a risk of more frequent drought due to declining of rainfall and increasing of temperature. They stated that the average annual minimum temperature over the country has increased by about $0.25{ }^{\circ} \mathrm{C}$ every decade, while average annual maximum

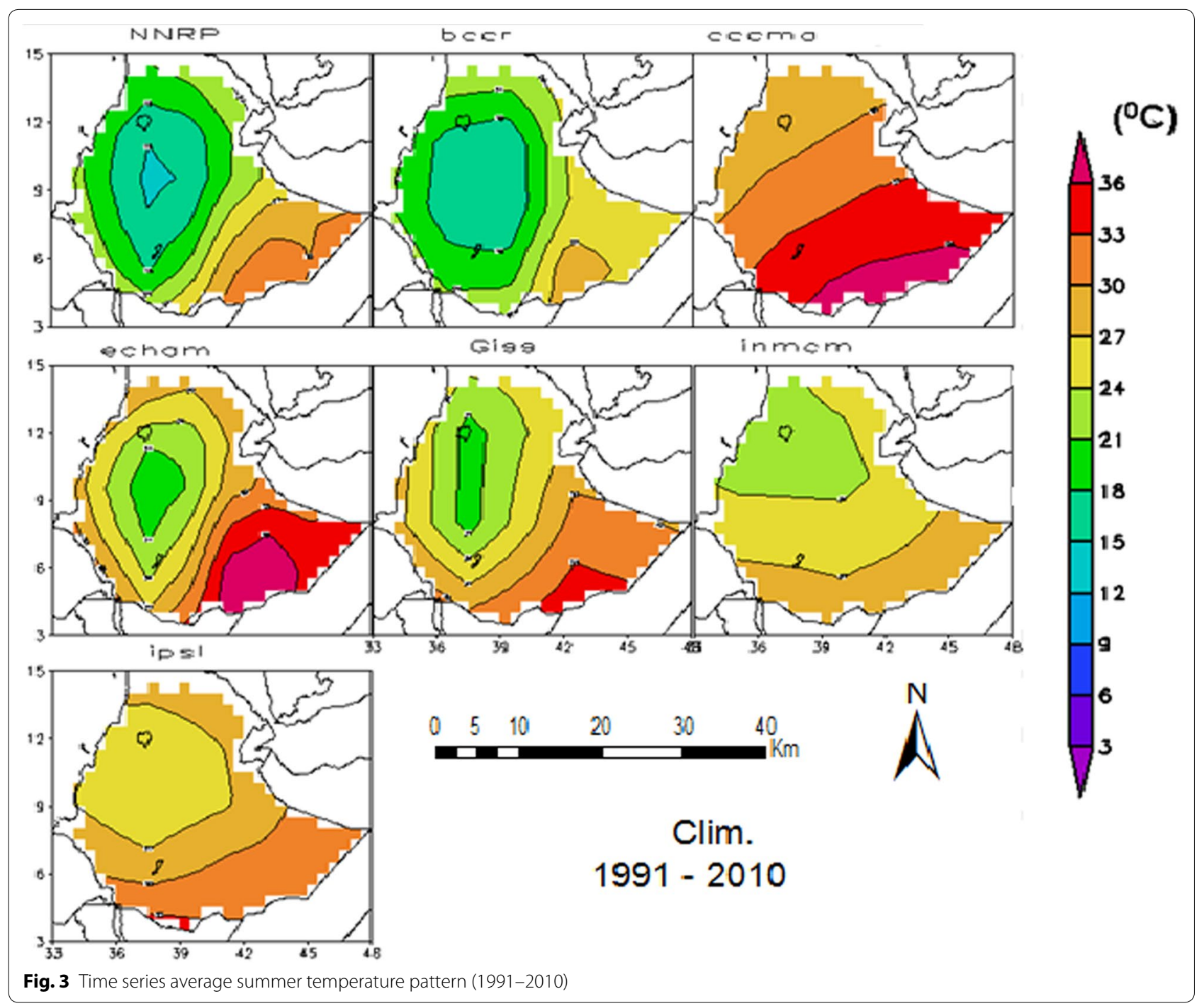


Table 8 Statistical analysis of summer temperature (20152034)

\begin{tabular}{llll}
\hline Model name & Clim $\left({ }^{\circ} \mathbf{C}\right)$ & sd & cv \\
\hline bccr & 21.851 & 0.487 & 2.231 \\
cccma & 32.840 & 0.332 & 1.011 \\
echam & 28.451 & 1.065 & 3.744 \\
giss & 27.169 & 0.276 & 1.018 \\
inmcm & 25.685 & 0.284 & 1.104 \\
ipsl & 28.714 & 0.266 & 0.925 \\
\hline
\end{tabular}

temperature has increased by $0.1{ }^{\circ} \mathrm{C}$ each decade. Moreover, they indicated that drought related disasters have increased over Ethiopia since 1970s and signals negative consequences on human, environment and the economy.

As it has been approved by the trend analysis of temperature from the observation data, GCM has also shown that a general increment of the summer temperature. These might be the cause for the prevalence of malaria in the Ethiopian highlands than ever before. Moreover, in the agricultural production system, the invasion of species as well as the deprivation of the indigenous species is the consequence of the change in the environment including temperature change. Animal disease and crop loss by the instantly created pest were a day to day phenomenon in Ethiopia. Therefore, predicting the future summer temperature of Ethiopia for the coming four decades, model bccr contribute a lot.

\section{Summer temperature outlooks (2015-2034)}

Understanding and predicting how the climate of Ethiopia will change over the next decades is an issue of urgent importance. Ethiopian society and its economy are strongly dependent upon its agriculture (Gulilat et al. 2008). It is clear therefore that relatively small changes in climate elements such as temperature will have large socioeconomic impacts. According to the best-performed model, the future summer temperature of the period 2015-2034 was found to be $21.85124{ }^{\circ} \mathrm{C}$. This value has increased by $0.72885{ }^{\circ} \mathrm{C}$ from the base period 1991-2010 and by $1.27661{ }^{\circ} \mathrm{C}$ from the base period 1971-1990 (Table 8).

Based on the normalized anomaly calculation, model bccr has predicted that more number of warm years than the previous periods. Except 2015 and 2016, worm and normal years have been predicted for the rest of the years. Out of the 20 years, seven have been predicted to be warm, two cold and the rest normal summer mean temperature (Table 9).

This model also has shown a very good performance in its past temperature analysis compared with the observation. Therefore, its recorded summer temperature would play an immense importance for policy makers and other

Table 9 Normalized anomaly of summer temperature (2015-2034)

\begin{tabular}{|c|c|c|c|c|c|c|}
\hline \multirow[t]{2}{*}{ Year } & \multicolumn{6}{|l|}{ Model } \\
\hline & $b c c r$ & cccma & echam & giss & inmcm & ipsl \\
\hline 2015 & -1.240 & -0.970 & -0.766 & -0.200 & -0.085 & 1.515 \\
\hline 2016 & -1.483 & -2.203 & -1.238 & 0.655 & 0.387 & -1.726 \\
\hline 2017 & -0.108 & 0.821 & -0.285 & 0.340 & -1.102 & 1.581 \\
\hline 2018 & 1.107 & 0.290 & 2.003 & 0.112 & -1.244 & -2.106 \\
\hline 2019 & 0.322 & -1.205 & -0.042 & 0.227 & -1.500 & -1.682 \\
\hline 2020 & -0.509 & -1.332 & 0.640 & 1.189 & -0.475 & 0.335 \\
\hline 2021 & 0.355 & 0.926 & -0.726 & 0.784 & -0.486 & -0.923 \\
\hline 2022 & 0.045 & -0.261 & 0.343 & -1.567 & 0.933 & 0.258 \\
\hline 2023 & 1.171 & -0.495 & 0.208 & 0.591 & 1.484 & -0.060 \\
\hline 2024 & -0.427 & -0.994 & -1.066 & -0.203 & 0.382 & 0.317 \\
\hline 2025 & 0.697 & 0.789 & 0.052 & 0.160 & 0.752 & 1.525 \\
\hline 2026 & 1.086 & 0.389 & -0.498 & -1.343 & -1.467 & -0.091 \\
\hline 2027 & 1.328 & 0.346 & -1.491 & -0.401 & 1.378 & 0.398 \\
\hline 2028 & 0.882 & -0.236 & 0.353 & 0.608 & -0.222 & -0.107 \\
\hline 2029 & 0.052 & 0.572 & 1.914 & 1.043 & -0.702 & 0.066 \\
\hline 2030 & 1.003 & 0.949 & 0.001 & 0.651 & 1.912 & 0.288 \\
\hline 2031 & 0.427 & 1.789 & 1.988 & -0.608 & 0.914 & -0.220 \\
\hline 2032 & 0.761 & 1.036 & -0.013 & 0.144 & -0.778 & 0.994 \\
\hline 2033 & 1.090 & -0.996 & -1.131 & -3.070 & 0.627 & 0.079 \\
\hline 2034 & 2.525 & 0.786 & -0.244 & 0.888 & -0.708 & -0.439 \\
\hline
\end{tabular}




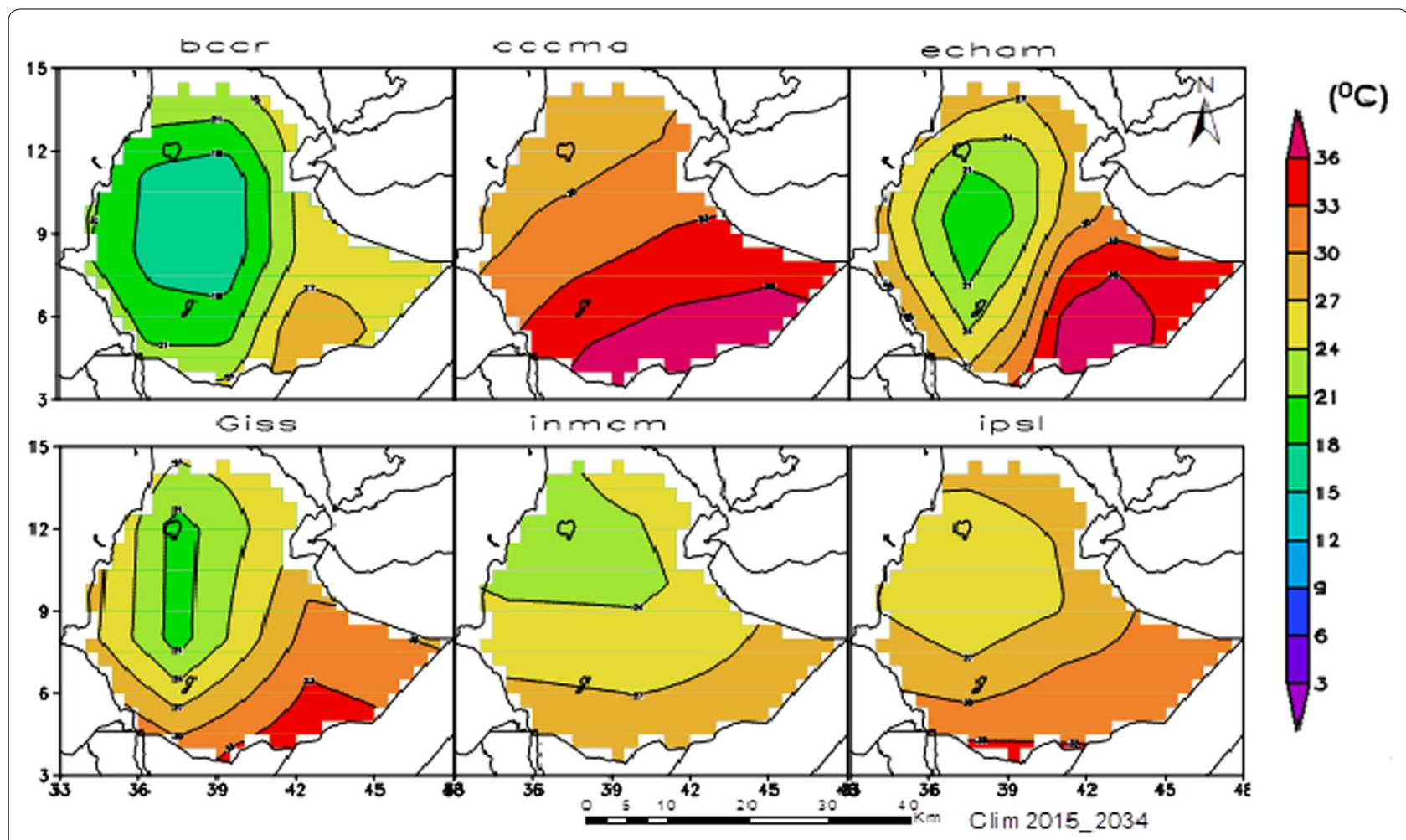

Fig. 4 Time series summer temperature pattern (2015-2034)

stakeholders in adapting and overcoming the consequences of the mean temperature change over the country. Moreover, it would contribute a lot to the selection of appropriate adaptation measures in selecting the right variety of crops and livestock for the predicted temperature ranges.

The spatial and temporal variations of the future temperature predictions have shown in Fig. 4. The patterns of the model bccr, echam and giss resembled each other and the values are closer as compared to the other three. Therefore, the value of the model $b c c r$ could be taken and important to take actions before the disasters which will be happened due to extremes of temperature in the country. Higher temperature may result in the invention of new species, creation of plant and animal pests, prevalence of malaria and related hazards would be managed once the warmest, the coldest and the normal years of temperature have predicted.

\section{Summer temperature outlooks (2035-2054)}

The summer temperature of the period 2035-2054 based on the model $b c c r$ was found to be $22.44137{ }^{\circ} \mathrm{C}$. This value is increased by $0.59013{ }^{\circ} \mathrm{C}$ from the period 2015 to
2034, $1.31898{ }^{\circ} \mathrm{C}$ from the base period 1991 to 2010 and $1.86674{ }^{\circ} \mathrm{C}$ from the period 1971 to 1990 . The mean summer temperature increased across periods by the model bccr (Table 10).

Based on the normalized anomaly value, the number of warmer years predicted to be increasing. Except the 2035, model bccr recorded warm and normal years (Table 11).

In the analysis of GrADS, The future summer temperature predictions have better represented by the model bccr, echam, giss, and inmcm based on the past records (Fig. 5). Higher temperature has been recorded by most of the models.

Table 10 Statistical analysis of summer temperature (2035-2054)

\begin{tabular}{llll}
\hline Model & $\mathbf{C l i m}\left({ }^{\circ} \mathbf{C}\right)$ & sd & cv \\
\hline bccr & 22.441 & 0.573 & 2.553 \\
cccma & 33.583 & 0.442 & 1.316 \\
echam & 28.222 & 1.196 & 4.238 \\
giss & 27.249 & 0.265 & 0.973 \\
inmcm & 25.804 & 0.462 & 1.790 \\
ipsl & 28.705 & 0.316 & 1.102 \\
\hline
\end{tabular}


Table 11 Normalized anomaly of summer temperature (2035-2054)

\begin{tabular}{|c|c|c|c|c|c|c|}
\hline \multirow[t]{2}{*}{ Year } & \multicolumn{6}{|l|}{ Model } \\
\hline & $b c c r$ & cccma & echam & giss & inmem & ipsl \\
\hline 2035 & -1.30156 & -0.23982 & 1.30082 & -0.31637 & -0.31579 & -0.14156 \\
\hline 2036 & 0.713461 & 0.669402 & -0.40007 & 1.711062 & -0.20081 & 1.142423 \\
\hline 2037 & 0.061947 & 0.588938 & -0.39305 & -0.3866 & 1.097353 & 0.107541 \\
\hline 2038 & 0.226238 & 0.184847 & 2.080953 & -0.93029 & 0.334498 & 0.261101 \\
\hline 2039 & 1.08294 & -0.27943 & -0.28473 & -1.21464 & 0.0469 & 0.548573 \\
\hline 2040 & 0.541471 & -0.14171 & -2.24713 & -0.00936 & -1.39397 & 1.028182 \\
\hline 2041 & -0.5646 & -2.49896 & -0.48473 & 0.806751 & 0.502629 & 1.53339 \\
\hline 2042 & 1.486996 & 0.128042 & 0.059789 & 0.260424 & -0.49555 & 0.65951 \\
\hline 2043 & 0.033793 & -1.34915 & 0.56702 & 1.106122 & 1.387351 & -1.69064 \\
\hline 2044 & -0.07265 & 0.874292 & 0.398034 & 0.893468 & 0.807256 & -1.28854 \\
\hline 2045 & 0.95166 & 0.152064 & -1.5464 & -0.4003 & 1.629768 & -0.51201 \\
\hline 2046 & 2.091573 & 1.372943 & 0.210411 & -0.45831 & 0.638212 & -1.60738 \\
\hline 2047 & -0.49334 & 1.781099 & 1.550836 & 2.283125 & -1.28267 & -1.59417 \\
\hline 2048 & -0.6029 & 0.42769 & -0.23542 & 0.922433 & 0.851752 & -0.48211 \\
\hline 2049 & 1.09799 & -1.06939 & -0.91743 & -0.99269 & -0.00583 & 1.098931 \\
\hline 2050 & 1.02979 & -0.81408 & 0.786115 & -1.78299 & -0.27963 & 0.483137 \\
\hline 2051 & -0.25986 & -0.02052 & -0.07611 & -0.81115 & 0.999085 & 0.805043 \\
\hline 2052 & 1.26427 & -1.24796 & -0.62907 & -0.69253 & -0.99523 & 0.602262 \\
\hline 2053 & 2.14859 & 1.212169 & -0.58501 & -0.0463 & -1.16573 & -1.31526 \\
\hline 2054 & 0.815348 & 0.269506 & 0.84515 & 0.058125 & -2.15962 & 0.361593 \\
\hline
\end{tabular}

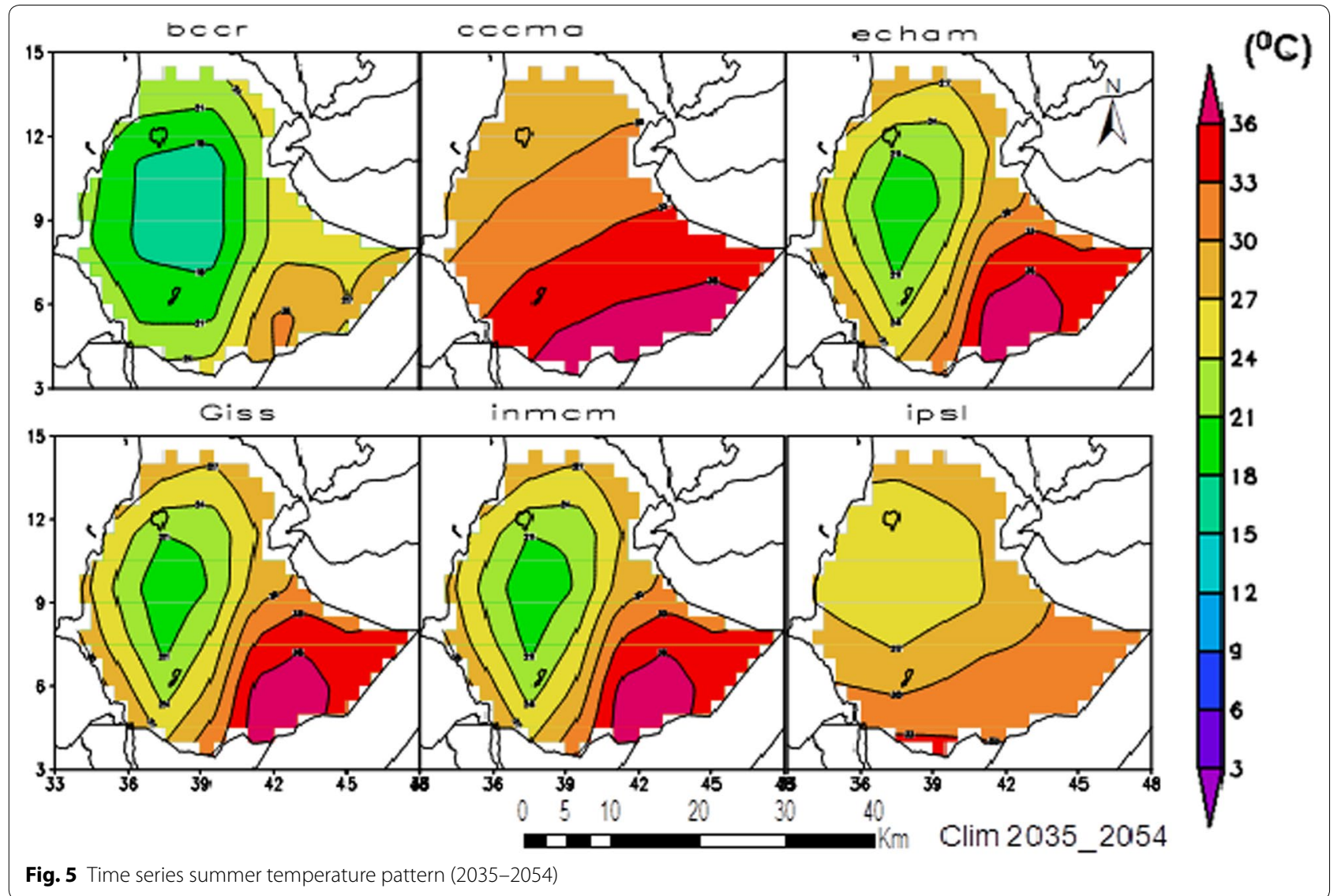


Table 12 Summary of summer temperature (1971-2010 and 2015-2054)

\begin{tabular}{|c|c|c|c|c|c|c|c|}
\hline Period & $N N R P$ & bccr & cccma & echam & giss & inmcm & ipsl \\
\hline 1971-1990 & 20.575 & 20.617 & 30.583 & 28.443 & 26.843 & 25.707 & 28.446 \\
\hline 1991-2010 & 21.122 & 21.283 & 31.510 & 28.491 & 27.003 & 25.606 & 28.540 \\
\hline Change & 0.548 & 0.666 & 0.928 & 0.048 & 0.161 & -0.101 & 0.094 \\
\hline 2015-2034 & & 21.851 & 32.840 & 28.451 & 27.169 & 25.685 & 28.714 \\
\hline $2035-2054$ & & 22.441 & 33.583 & 28.222 & 27.249 & 25.804 & 28.705 \\
\hline Change & & 0.590 & 0.743 & -0.229 & 0.080 & 0.119 & -0.009 \\
\hline
\end{tabular}

\section{Conclusions}

From the overall analysis of the past four decades of summer mean temperature, the following conclusions are drawn. The summer temperature of the past four decades has been changed by $0.548{ }^{\circ} \mathrm{C}$ and based on the best performed model (bccr and cccma), it has predicted to increase by 0.59 and $0.743{ }^{\circ} \mathrm{C}$, respectively by the next four decades (Table 12). Therefore, based on this research findings, it is possible to recommend the policy makers and other concerned bodies to consider the increasing summer temperature while planning the future development strategies.

\section{Acknowledgements}

This study would never be completed without the contribution of many people to whom I would like to express my gratitude. Professor P.V.V. Prasada Rao, Murali Negasa Rao, and Meteorology and oceanography staff of the Andhra University, and final to the Bahir Dar University, College of Agriculture and Environmental Sciences staff for their academic contribution during the data collection, analysis and write up of this research.

\section{Competing interests}

The author declare that there is no competing interest.

Received: 29 March 2016 Accepted: 10 November 2016

Published online: 05 December 2016
Gulilat TD, Thomas T, Len S (2008) Ethiopian rainfall in climate models. http:// climate.ncas.ac.uk/len/african_climate/ethiopia_climate_models_draft_ nofigs.pdf. Retrieved April 2013

IPCC (2001a) Climate change 2001, the scientific basis. Cambridge University Press, Cambridge

IPCC (2001b) Climate Change 2001: impacts, adaptation and vulnerability. Cambridge University Press, Cambridge

McSweeney C, New M, Lizcano G (2008) UNDP climate change country profile Ethiopia. School of Geography and Environment, University of Oxford and Tyndall Center for climate change research

NMSA (National Meteorological Service Agency) (2001) Initial National Communication of Ethiopia to the United Nations Framework Convention on Climate change. National Meteorology service Agency, Addis Ababa

NMSA (National Meteorological Service Agency) (2007) Climate Change National Adaptation Program of Action (NAPA) of Ethiopia. NMSA, Addis Ababa. Retrieved June 23, 2013, from NMSA database

Schindelegger M, Ray RD (2014) Surface pressure tide climatologist deduced from a quality-controlled network of barometric observation. Mon Weather review J 142:4872. doi:10.1175/MWR-D-14-00217.1

Legesse SA (2016) The outlook of Ethiopian long rain season from the global circulation model. Environ Syst Res 5:16. doi:10.1186/s40068-016-0066

Temesgen G, Aleme A, Mulata H (2014) Climate change and livestock production in Ethiopia. Adv Life Sci Technol J 22:2224-7181

UNEP (United Nations Environment Programme) (2007) Eastern Africa and freshwater resources. In: Africa environment outlook 2: our environment, our wealth (e-book). Encyclopedia of Earth (eds). Washington: Environmental Information Coalition, National Council for Science and the Environment

UNFCCC (United Nations Framework conventions on Climate Change) (2006). Background paper on Impacts, Vulnerability and adaptation to climate change in Africa. 1 CP.10, Accra, Ghana, September 2006

Yatagai A, Osamu A, Kenji K, Haraku K, Masato I, Atsushi H (2009) A 44 year daily gridded precipitation data set for Asia based on a dense network of rain gauges. SOLA 5:137-140. doi:10.2151/sola.2009-035

\section{References}

Compo GP, Whitaker PD, Sardeshmukh N, Matsui RJ, Allan X, Yin BE, Gleason RS, Vose G, Rutledge P, Bessemoulin S, Brönnimann M, Brunet RI, Crouthamel AN, Grant PY, Groisman PD, Jones M, Kruk AC, Kruger GJ, Marshall M, Maugeri HY (2011) The twentieth century reanalysis project. Q J Roy Meteorol Soc 137:1-28. doi:10.1002/qj.776

CSA (Central Statistical Agency) (2007) Central Statistical Agency Population and Housing Census of Ethiopia, Addis Ababa. Retrieved August, 2013, from CSA database

Elasha BO, Medany M, Niang-Diop I, Nyong T, Tabo R, Vogel C (2006) Background paper on impacts, vulnerability and adaptation to climate change in Africa for the African Workshop on Adaptation Implementation of Decision 1/CP.10 of the UNFCCC Convention, Accra, Ghana, 21-23 September, 2006. pp 54

\section{Submit your manuscript to a SpringerOpen ${ }^{\odot}$ journal and benefit from:}

- Convenient online submission

- Rigorous peer review

- Immediate publication on acceptance

- Open access: articles freely available online

- High visibility within the field

- Retaining the copyright to your article

Submit your next manuscript at springeropen.com 